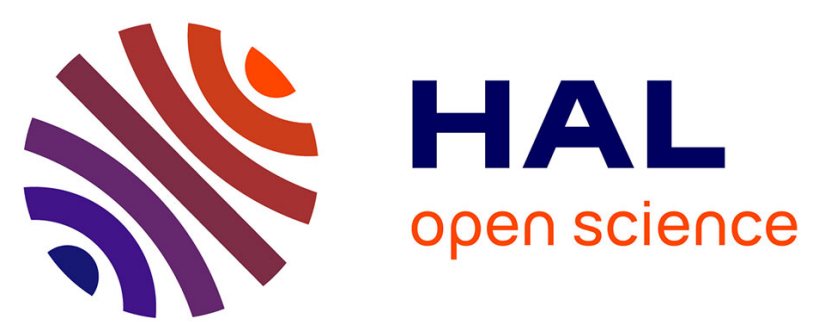

\title{
Structure-reactivity relationships in fuel stability: Experimental and kinetic modeling study of isoparaffin autoxidation
}

Karl Chatelain, André Nicolle, Arij Ben Amara, Laurie Starck, Laurent

Catoire

\section{To cite this version:}

Karl Chatelain, André Nicolle, Arij Ben Amara, Laurie Starck, Laurent Catoire. Structure-reactivity relationships in fuel stability: Experimental and kinetic modeling study of isoparaffin autoxidation. Energy \& Fuels, 2018, 32 (9), pp.9415 - 9426. 10.1021/acs.energyfuels.8b01379 . hal-01935235

\section{HAL Id: hal-01935235 \\ https://hal-ifp.archives-ouvertes.fr/hal-01935235}

Submitted on 26 Nov 2018

HAL is a multi-disciplinary open access archive for the deposit and dissemination of scientific research documents, whether they are published or not. The documents may come from teaching and research institutions in France or abroad, or from public or private research centers.
L'archive ouverte pluridisciplinaire HAL, est destinée au dépôt et à la diffusion de documents scientifiques de niveau recherche, publiés ou non, émanant des établissements d'enseignement et de recherche français ou étrangers, des laboratoires publics ou privés. 


\title{
Structure-reactivity relationships in fuel stability: Experimental and kinetic modeling study of isoparaffin autoxidation
}

\author{
Karl Chatelain ${ }^{\star, a, b}$, André Nicolle ${ }^{\mathrm{a}}$, Arij Ben Amara ${ }^{\mathrm{a}}$, Laurie Starck ${ }^{\mathrm{a}}$, Laurent Catoire ${ }^{\mathrm{b}}$ \\ a: Institut Carnot IFPEN Transports Energie, IFP Energies nouvelles, 1-4 avenue de Bois-Préau 92852 Rueil-Malmai- \\ son Cedex, France \\ b: ENSTA ParisTech, Université Paris-Saclay, laboratoire UCP, 828 Boulevard des Maréchaux 91762 Palaiseau, \\ France \\ Keywords: Oxidation, alkanes, normal paraffins, isoparaffins, autoxidation, liquid phase, detailed chemistry modeling
}

\begin{abstract}
Liquid phase stability is a major concern in the transportation and the energy field where fuels, lubricants and additives have to be stable from their production site to their application (engine, combustors). Although alkanes are major constituents of commercial fuels and well-documented solvents, their respective reactivities and selectivities in autoxidation are poorly understood. This experimental and modeling study aims at (i) enhancing the current knowledge on alkane autoxidation and (ii) reviewing and correcting the previously established structure reactivity relationships in alkane autoxidation. Experimentally, this study investigates the influence of branching [o-3] and temperature [373-433 K] on the autoxidation of alkanes using four octane isomers: n-octane (C8), 2-methylheptane (MH), 2,5-dimethylhexane (DMH) and the 2,2,4-trimethylpentane(TMP). Induction Period (IP) and qualitative species identification are used to characterize the autoxidation processes of alkanes. The present study also presents new detailed liquid-phase chemical mechanisms obtained with an automated reaction mechanism generator. Experimental results highlight a non-linear effect of the paraffins branching on IP according to compound structure and similar oxidation products for both normal and branched paraffins. The four iso-octanes mechanisms reproduce fairly well the temperature and the branching effects on IP within a factor of 4 for high temperature range $(\mathrm{T}>403 \mathrm{~K})$. From rate-of-reaction and sensibility analyses, similarities in alkane autoxidation have been evidenced with notably the key role of peroxy radicals in both normal and branched alkane autoxidation. The origin of the structure-reactivity relations was confirmed from a kinetic point of view with the main role of the hydrogen type on the molecule. Finally, based on experimental results available in literature, an empirical relation involving simple descriptors (number of carbons, type of carbons, temperature) is proposed to estimate alkane stability.
\end{abstract}

\section{INTRODUCTION}

Liquid-phase stability is a major concern in the transportation and energy fields, as it involves the degradation of widely used fluids, such as fuels, lubricants, and additives throughout their lifecycle. For instance, liquid-phase oxidation can occur under many different conditions, such as pyrolytic/oxidative, photochemically activated, microbiological (aerobic or anaerobic), atmospheric or pressurized conditions. Different applications can be impacted by hydrocarbon oxidation in the liquid phase such as fuel stability under storage $^{1}$ or operating conditions ${ }^{2}$ to human nutrition, cosmetics and fragrances 3 .

The fuel and transport field is constantly changing due to recent environmental considerations with the reduction of greenhouse gas emissions and the need to improve local air purity. Those considerations impact fuel compositions with the increasing use of biofuels. In addition, technology improvements on both fuel and combustion lead to a diversification of additive packages whose chemistry and their interactions with conventional fuel fractions are poorly assessed. The complex autoxidation chemistry coupled to the strongly varying pressure ${ }^{4}$ and temperature conditions ${ }^{5-7}$ involved in automotive and aircraft injection systems result in an increase of fuel stress. Those stresses may in turn induce jet and diesel fuels autoxidation through spontaneous free radical oxidation at low temperature, which influences physical and chemical properties and leads to the formation of several oxidation products that finally gives deposits on the fuel system.

While commercial fuels are complex hydrocarbon blends, most literature studies involve global chemical mechanisms with lumped species ${ }^{8-10}$ for pure components autoxidation. However, more recent studies involve detailed liquid phase mechanisms $\mathrm{s}^{11-14}$ with relevant thermochemical and kinetic data that include isomer distinctions to better capture the complexity of autoxidiation.

Although alkanes are major constituents of commercial fuels and well-documented solvents, their respective reactivities and selectivities in autoxidation are poorly understood with non linear effects. Thus, within the framework 
of the full comprehension of fuel stability, this work confirms and extends previous work performed on the autoxidation of normal parraffins ${ }^{12,15-19}$ to isoparaffins ${ }^{17,20,21}$. The present study is in-line with others autoxidation studies performed at IFPEn on aromatics ${ }^{14,22}$ and naphthenes ${ }^{22}$. All these studies aim at improving the comprehension of the autoxidation of each chemical family present in fuels. These preliminary studies are mandatory for the establishment of universal structure-reactivity or empirical relations, like the ones commonly used to estimate fuel prop$\operatorname{erties}^{23-25}$ or gas phase combustion ${ }^{26,27}$. Several works evidenced the structure-reactivity relationship for n-paraffins presenting an increase of the oxidation rate with the chain length $^{12,15,17,28}$. However, the effect of the branching was not widely studied ${ }^{17,29}$ and the results available do not present the same conclusions. The results from Stark et al. tend to indicate an increase of the oxidation rate with the branching, while Skolniak et al. evidenced a stability increase based on PetroOxy measurements. The current study aims to revisit and to correct the statement on the branching effect on alkane autoxidation based on new experimental data and detailed kinetic modeling.

We herein experimentally investigate the influence of the branching and temperature $(373-433 \mathrm{~K})$ on the autoxidation of alkanes for four different octane isomers: n-octane $\left(\mathrm{C}_{8}\right)$, 2-methylheptane $(\mathrm{MH})$, 2,5-dimethylhexane (DMH) and the 2,2,4-trimethylpentane(TMP). Our measurements include both Induction Period (IP) and speciation analysis for their individual oxidation. The present study also develops original detailed liquid-phase chemical mechanisms for several iso-alkanes using an automated mechanism generator. Macroscopic reactivity descriptors such as IP, combined to topological ones, obtained from GC-MS analyses, are herein used to emphasize similarities and discrepancies in alkane autoxidation processes.

\section{EXPERIMENTAL SETUP}

Experiments were performed with a PetroOxy apparatus from Petrotest Instruments $\mathrm{GmbH}$ \& Co. KG. Previous works $3,12,12,30,31,31,32$ have successfully employed this device to study liquid phase autoxidation kinetics. High purity liquid alkanes (99\%) and dioxygen (99.9\%) were selected to reduce catalytic effect of trace species during experiments. The purity of these compounds was controlled by both GCMS and GC-FID respectively for identification and quantitative estimation. The impurities detected were different branched alkanes within the $1 \%$ impurity. All results from the present study were obtained with $5 \mathrm{~mL}$ of samples and 7 bars of initial oxygen. Complementary information on the overall working procedure of PetroOxy device is available in literature ${ }^{12}$.

From this experiment, we can extract the IP which corresponds to the time required to reach a $10 \%$ pressure decrease $\left(\mathrm{P}_{\mathrm{IP}} / \mathrm{P}_{\max }=0.9\right)^{33,34}$ as presented on Figure 1 . This criterion commonly corresponds to $5 \%$ of fuel consumption $^{11,30,35}$ and corresponds to the hydroperoxide build up and first deposit precursors formation. A typical experimental result is presented in Figure 1 which shows that the time to reach the requested temperature is included in the IP. This delay is below four minutes in all experiments and is therefore negligible regarding to IP and the measurements reproducibility presented in the experimental results section.

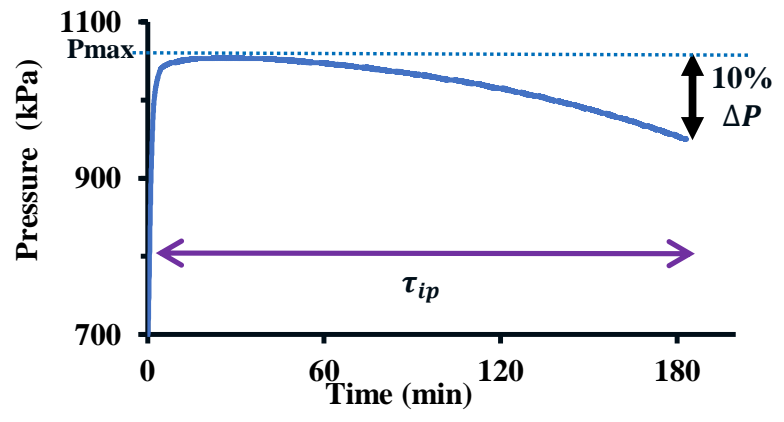

Figure 1: Typical pressure signal obtained during the autoxidation of n-decane 12 at $413 \mathrm{~K}$ using a PetroOxy experiment with $700 \mathrm{kPa}$ of initial oxygen.

The experiment is stopped at IP and liquid residuals are analysed with a Gas Chromatograph (GC) 6890 from Agilent equipped with a split/splitless injector coupled to a Mass Spectrometer (MS) 5973 from Agilent. The MS fragmentation is performed by electron impact $(7 \mathrm{o} \mathrm{eV})$ and the detection with a quadrupole detector in full scan mode ( $\mathrm{m} / \mathrm{z}$ mass range from 10 to 400 ). Due to the diversity of products formed during autoxidation processes, a high polarity column DB-FFAP (6o m, $0.250 \mathrm{~mm}$ inner diameter, $250 \mu \mathrm{m}$ film thickness), was used to allow proper identification with limited co-elution phenomena using appropriate GC settings (carrier gas: He, injector temperature: $350^{\circ} \mathrm{C}$, initial column pressure: $11.6 \mathrm{psi}$, constant flow: $0.5 \mathrm{~mL} / \mathrm{min}$, split ratio: $75: 1$, oven temperature program: $\mathrm{T}_{\text {init }}=40^{\circ} \mathrm{C}$ for 1omin, then $5^{\circ} \mathrm{C} / \mathrm{min}$ up to $100^{\circ} \mathrm{C}$ without holding time and $1^{\circ} \mathrm{C} / \mathrm{min}$ up to $\left.250^{\circ} \mathrm{C}\right)$.

\section{MODELING APPROACH}

The present modeling methodology is based on Reaction Mechanism Generator (RMG) ${ }^{36}$ to generate the liquid phase kinetic models and a zero-dimensional reactor mode $^{1,12}$ for the validation steps. RMG code and its liquidphase thermokinetic corrections have been described earlier in literature ${ }^{36-38}$. For all presented mechanisms, the solvent reacts in itself. For this reason, each mechanism cannot be directly used for another chemical system due to solvent corrections.

Mechanisms were generated with RMG-Java 3.o.1 version upgraded with all relevant new reaction families of RMGJava 4.0.1, mostly Korcek's reactions and some specific intra molecular reaction families. Mechanisms generation was performed with all reaction families except the sulfur-specific ones. The thermochemical and transport libraries from the GRI 3.0 mechanism were selected and all other kinetic libraries were kept empty. Solvation correction to the thermochemical data is considered in the generation 
using Mintz and Abraham's correlation. Solvent parameters were already available in the RMG libraries for n-octane and "isooctanes". The distinction between all branched octane isomers was also not performed in the referenced paper ${ }^{39,40}$. For this reason, Mintz (Mtz) and Abraham's $(A b r)$ parameters were respectively fixed over all branched octane isomers as presented in Equation 1. Initial conditions such as concentrations, viscosities, oxygen solubility were computed for each system from data available in the literature ${ }^{41,42}$.

Equation 1: Equations presenting the evolution of a given Abraham and Mintz's parameter between all branched $C_{8}$ isomers. Similar evolution must be consider for all parameters $(i=1,2 \ldots, n)$.

$$
\begin{aligned}
& A b r_{i, M H}=A b r_{i, D M H}=A b r_{i, T M P} \text { and } A b r_{i, M H} \neq A b r_{i, C 8} \\
& M t z_{i, M H}=M t z_{i, D M H}=M t z_{i, T M P} \text { and } M t z_{i, M H} \neq M t z_{i, C 8}
\end{aligned}
$$

For each alkane, the mechanisms were subsequently enhanced by including more intermediates and oxidation products from the first alkyl radical formation to the formation of both light carbonyls and light acids. The final termination criterion selected for the detailed models corresponds to $50 \%$ conversion. This conversion level allows to (1) keep the initial n-alkane as a major constituent throughout the generation condition, (2) to let generation proceed until the second stage of oxidation, which involves notably the formation of polyfunctional species, and (3) to get relevant reaction paths for deposit precursors. In this manner, solvent effects would rely mainly on the nature of the fuel, while oxygenated products contribution may be considered as negligible.

The generated mechanisms were coupled to a previously developed reactor model to reproduce experimental results $^{1,12,14}$. This reactor model includes a constant-concentration option for species specified in the input file. This feature is required to represent $\mathrm{O}_{2}$ concentration in the modeling of bulk autoxidation in kinetic limited regime.

\section{RESULTS AND DISCUSSIONS}

\section{Experimental results}

To identify the effect of the branching on alkanes reactivity, experiments are conducted over a wide temperature range (373-433 K) on the four C8 alkanes at $700 \mathrm{kPa}$ of initial oxygen. To obtain meaningful data, acquisition of IP below 0.5 hours was not attempted due to (i) the significant heating time over IP ratio $\left(\frac{\text { heating time }}{I P}\right)$ (ii) such low IPs are commonly obtained for high temperature conditions under which the volatility of compounds may be not neglected anymore. Experiments were conducted with high purity compounds ( $\geq 99 \%)$. The impact of impurities $\left(\Delta I P_{99 \% \rightarrow 99.8 \%}[\right.$ hours $\left.]=0.13 \times I P_{99 \%}\right)$ was previously established for $n$-alkanes ${ }^{12}$ in similar conditions based on: the $1 \%$ impurity contribution, the IP value and the reproducibility. The effect of impurities is assumed to be similar in the present study and is presented with uncertainty bars on the experimental results. All experimental conditions investigated per chemical compound are summarized in Table 1.

Table 1: Summary of experimental conditions tested in the present work. C8, MH, DMH and TMP respectively stand for n-octane, 2-methylheptane, 2,5-dimethyllhexane, 2,2,4-trimethylpentane. '\#' stands for the number of branching. $P_{O_{2}, \text { ini }}$

\begin{tabular}{|c|c|c|c|c|c|}
\hline $\begin{array}{l}\text { Com- } \\
\text { pound }\end{array}$ & $\begin{array}{l}\text { Molecule } \\
\text { Structure }\end{array}$ & Purity & $\begin{array}{c}\text { Formula } \\
(\#)\end{array}$ & $\begin{array}{c}\text { Temp. } \\
\text { range }[K]\end{array}$ & $\begin{array}{l}P_{\mathrm{O}, \mathrm{ini}} \\
{[\mathrm{kPa}]}\end{array}$ \\
\hline C8 & & & $\overline{\mathrm{C} 8 \mathrm{H}_{1} 8(\mathrm{o})}$ & & \\
\hline$M H$ & & & $\mathrm{C} 8 \mathrm{H}_{18} 8$ (1) & & \\
\hline$D M H$ & & $\geq 99 \%$ & $\mathrm{C} \mathrm{H}_{18} 8$ (2) & $373-433$ & 700 \\
\hline TMP & & & $\mathrm{C} \mathrm{H}_{18} \mathrm{C}_{3}$ (3) & & \\
\hline
\end{tabular}
stands for the initial pressure.

Temperature impact

Figure 2 presents the evolution of IP with temperature reciprocal for all molecules tested. Although additional data would be required for temperatures lower than $393 \mathrm{~K}$, the IP seems to decrease exponentially with the temperature reciprocal for $\mathrm{C} 8, \mathrm{MH}, \mathrm{DMH}$ and TMP. The fair quality of the regression for $\mathrm{C} 8, \mathrm{MH}, \mathrm{DMH}$ indicates that their global autoxidation follows an Arrhenius form with an apparent $\mathrm{A}^{\prime}$ and Ea' presented in Figure 2, in line with literature ${ }^{11,12}$. While a fair regression is presented for TMP, two distinct oxidation regimes can be distinguished for temperatures higher and lower than $403 \mathrm{~K}$. In addition, the comparison of apparent Ea' emphasizes a specific oxidation behavior of the TMP which has a much smaller apparent activation energy than $\mathrm{n}-\mathrm{C} 8, \mathrm{MH}$ and $\mathrm{DMH}$.

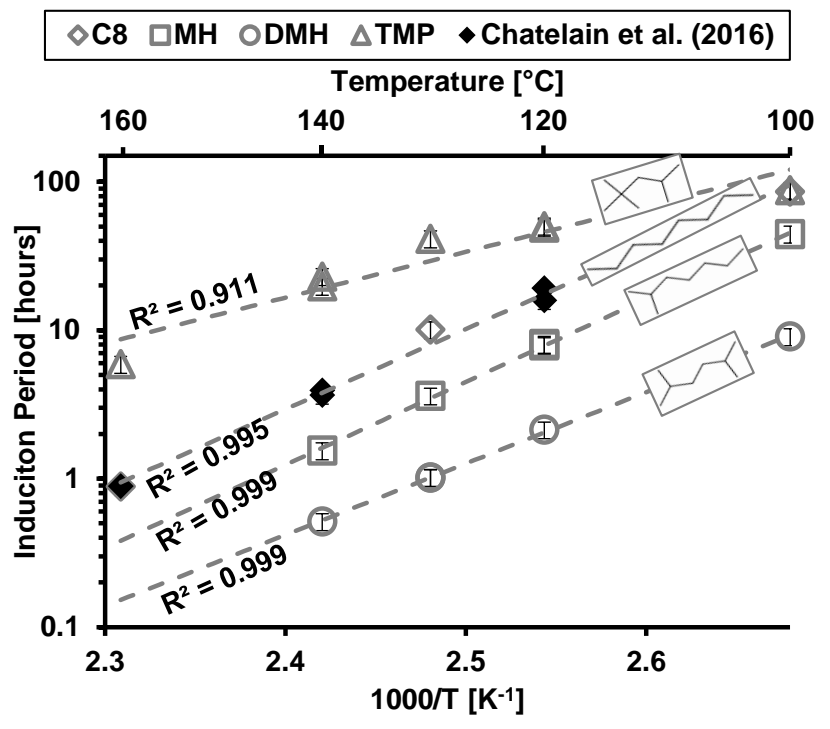

Figure 2: IP measurements obtained with the four molecules obtained at 373-433 K and 70o kPa of initial oxygen. Uncertainties are calculated including PetroOxy repeatability and compound purity. The least-square regression corresponds to the Arrhenius fit $I P=A^{\prime} \times \exp \left(E a^{\prime} / R T\right)$. For which $A^{\prime}[h]$ and $E a^{\prime} / R=T a^{\prime}[K]$ parameters respectively correspond to: $2.30 \times 10^{-13}$ and 12.6 for $C 8$, $4.72 \times 10^{-14}$ and 12.9 for $\mathrm{MH}, 1.24 \times 10^{-12}$ and 11.1 for $\mathrm{DMH}, 6.65 \times 10^{-7}$ and 7.1 for TMP. 


\section{Branching impact}

Figure 3 and Figure 4 present the evolution of IP over the number of branchings for several temperatures. The IP is inversely proportional to the branching level for $\mathrm{C} 8, \mathrm{MH}$ and $\mathrm{DMH}$ but does not follow this trend for the third branching (TMP). An exponential regression is presented on Figure 3 and Figure 4 to better characterize this decreasing trend within the $0-2$ range. Thus, except for the $100^{\circ} \mathrm{C}$ case, the exponential regressions are in good agreement with experimental data and they give an error below the experimental uncertainties in most conditions. As pointed out in Figure 2 depicting the temperature effect, a specific behavior of the TMP is also observed with the branching effect. While the Bond Dissociation Energy (BDE) of $\mathrm{C}-\mathrm{H}$ bonds explains the reactivity increase within the range [o2], the TMP which also has a tertiary carbon has a slower reactivity than all others molecules tested. Yet, as presented in Table 1 , the TMP is the only compound with a quaternary carbon on which there is no more $\mathrm{H}$ to abstract. This demonstrates that more relevant descriptors are required to classify alkanes oxidability. Further discussions on these structure-reactivity relationship and their origins are provided in the last section of this work (section 4).

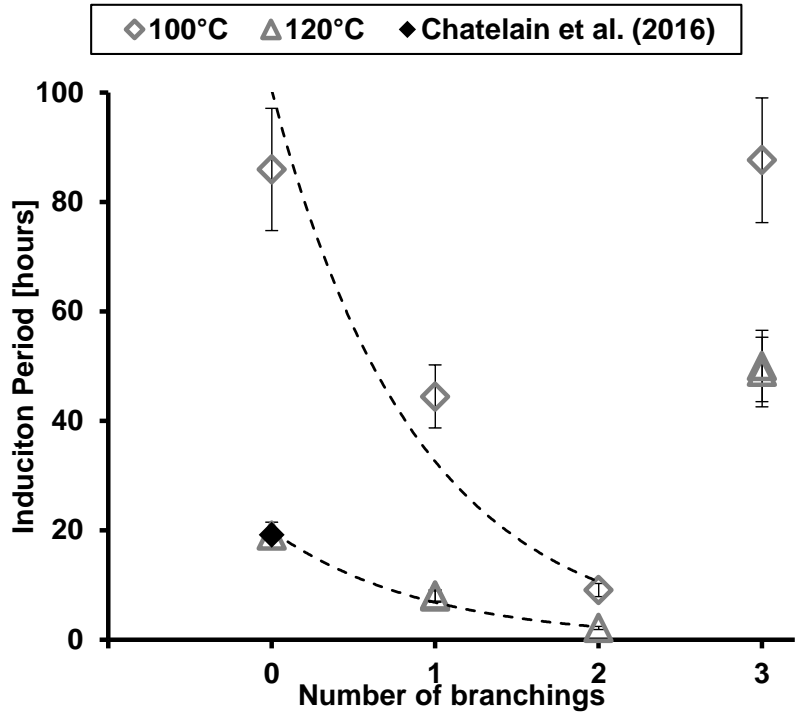

Figure 3: IP variation of several $C_{8}$ alkanes as function of temperature and branching level obtained at 373-393 K and $700 \mathrm{kPa}$ of initial oxygen. Uncertainties are calculated including PetroOxy repeatability and compound purity. Exponential regression is presented in dashed lines. $\triangle 120^{\circ} \mathrm{C} \quad \square 130^{\circ} \mathrm{C} \quad 0140^{\circ} \mathrm{C} \bullet$ Chatelain et al. (2016)

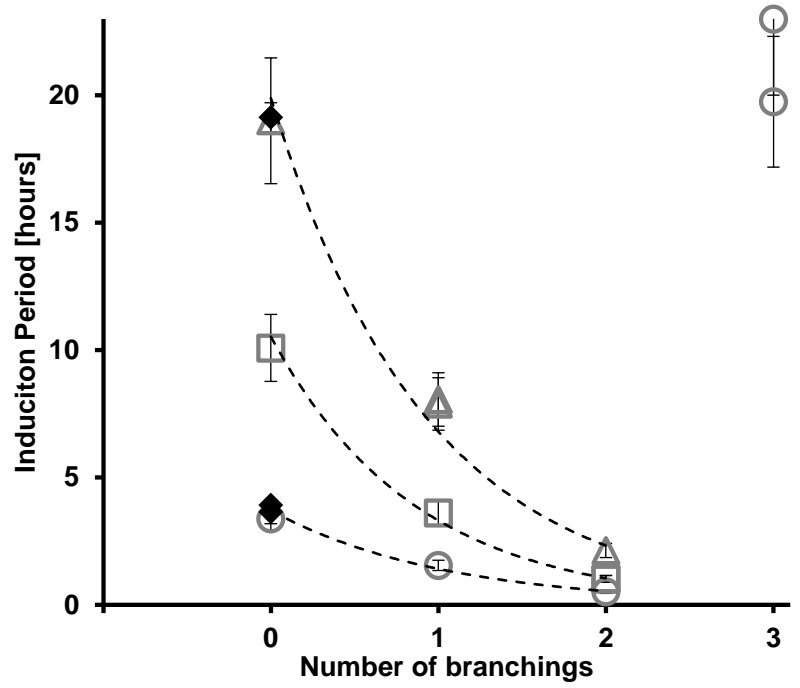

Figure 4: IP variation of several C8 alkanes as function of temperature and branching level obtained at 403-443 K and 70o $\mathrm{kPa}$ of initial oxygen. Uncertainties are calculated including PetroOxy repeatability and compound purity. Exponential regression is presented in dashed lines.

\section{Speciation analysis}

At the end of the experiment, liquid phase residuals are collected for off-line analysis. Table 2 presents products identified by chemical family for all C8 alkanes studied in the present work. Except for the TMP, similar oxidation products were identified over the temperature range 373$433 \mathrm{~K}$. TMP analyses did not reveal a significant amount of oxygenated species for the low temperature range (s $393 \mathrm{~K}$ ), while both C8 ketones and alcohols where observed at higher temperature $(\geq 403 \mathrm{~K})$. This tends to demonstrate two oxidation regimes of TMP respectively below $400 \mathrm{~K}$ and above $400 \mathrm{~K}$ in the absence of possible experimental bias for long IP measurements. In addition, the following general rule is observed: the more branched the reactant is, the less diverse the oxidation products are. This statement should however be further qualified as (i) there are less and less isomers distinction with an increasing number of branching, (ii) the small number of products formed are highly concentrated compared to the minor, (iii) the MS spectrum is more complicated to analyze and (iv) more volatile compounds are formed with an increase of branching (like $\mathrm{CO}_{2}, \mathrm{H}_{2}$, and light hydrocarbons below $\mathrm{C}_{4}$ ). For all the 4 compounds, hydroperoxides were not detected due to the weak $\mathrm{O}-\mathrm{O}$ bonds, which are known to thermally decompose into the injector and/or the GC-oven. 
Table 2: Similarities and differences of oxidation products formed between the tested isomers of C8. $\sqrt{ }, X$ and $\sim$ signs respectively mean compounds identified, not identified and traces suspected.

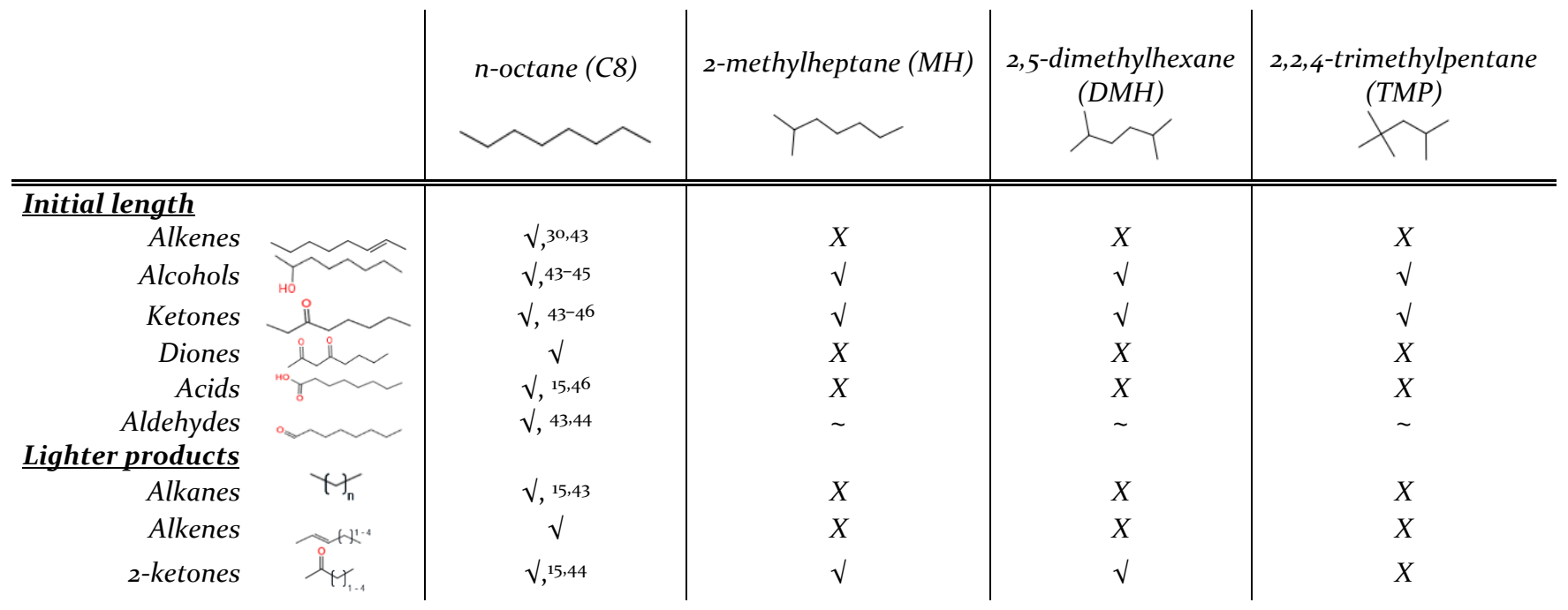

\section{Modeling results}

\section{Temperature effect}

Data from the literature and the present study were used for the model validation on IP prediction. Table 3 presents literature data and the associated methods to reconstruct IPs. Figure 5 to Figure 8 present the agreement of models prediction (black solid lines) with IP criterion for all molecules tested. To assess models performance, least-squares regressions (dashed blue lines) are performed on present study data (blue symbols). The new experimental data are in agreement with literature data and emphasizes the good reproducibility of PetroOxy experiments. An $\mathrm{O}_{2}$ fraction variation is performed from 50 to $20000 \mathrm{ppm}$ to assess the sensibility of the models prediction to the liquid oxygen concentration. This variation corresponds to a factor 20 variation applied on the 10ooppm $\mathrm{O}_{2}$ concentration, which is considered as the correct order of magnitude of dissolved $\mathrm{O}_{2}$ in standard conditions. Thus, the choice of the upper limit $(2 \%)$ corresponds to the expected dissolved oxygen considering 7 bar initial pressure and no temperature dependence of the Henry's coefficient for isooctanes. In addition, the 5oppm condition allows to assess the sensibility of the modeled IP for conditions far from ideal (in the case of non-homogenous oxygen concentration with local heterogeneity. Thus, the lines of the model represented in Figure 5 to Figure 8 correspond to the average value and the error bars corresponds to the IPs variations induced by the concentration changes. Interestingly, two distinct effects of $\mathrm{O}_{2}$ fractions are observed, on both n-C8 and TMP the relative error is increasing with temperature while it is almost constant in both MH and DMH.

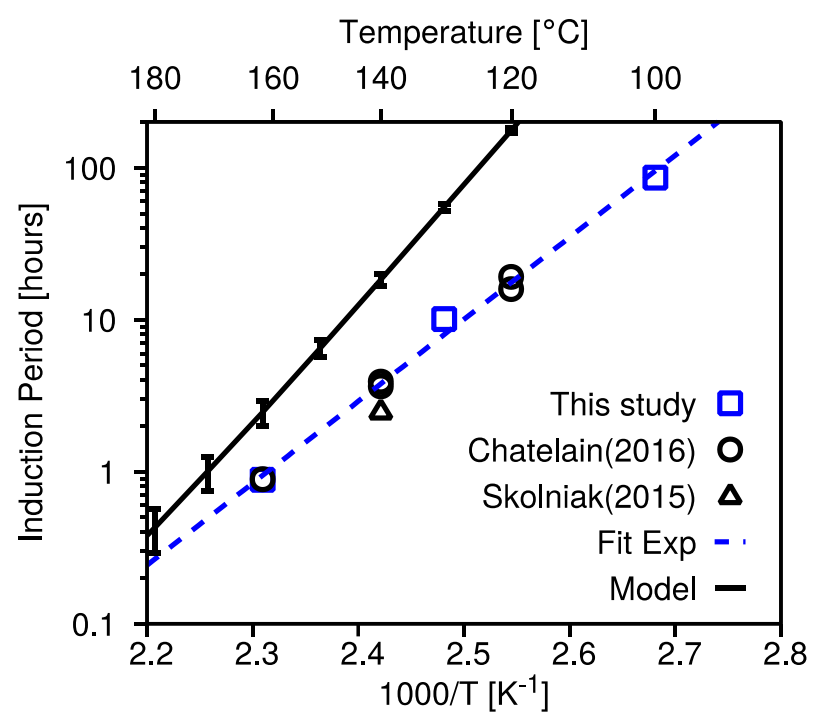

Figure 5: N-octane model prediction on IP against present study (blue symbols) and literature data (black symbols). For clarity sake, a regression on present study data (dashed blue line) is performed to assess models (solid black lines) performance. Uncertainty bars represent the IP variation regarding to the oxygen dissolved into liquid. The minimum and maximum respectively corresponds to 50 ppm and $2 \%$ of initial oxygen. 
Table 3: Summary of literature data used for validation. Operating conditions and detection techniques are given to make comparison easier between experimental data. "5\% fuel consumption" means that IP is obtained when $5 \%$ of the initial fuel is converted. The approximate (“ ") final pressure and oxygen consumption are both a consequence of the fixed initial pressure (7ookPa) and the evolution of the compound volatility over the temperature range investigated.

\begin{tabular}{|c|c|c|c|c|}
\hline Data label & Reactor & Mixture & $\begin{array}{l}\text { Pressure } \\
(\mathrm{kPa})\end{array}$ & IP definition \\
\hline \multicolumn{5}{|l|}{ Octane } \\
\hline This study & PetroOxy & $\mathrm{C}_{8}+\mathrm{O}_{2}$ & $\sim 1000$ & $\sim 10 \%$ oxygen consumption \\
\hline Chatelain et al. (2016) ${ }^{12}$ & PetroOxy & $\mathrm{C}_{8}+\mathrm{O}_{2}$ & $\sim 1000$ & $\sim 10 \%$ oxygen consumption \\
\hline Skolniak (2015) $)^{17}$ & PetroOxy & $\mathrm{C}_{8}+\mathrm{O}_{2}$ & $\sim 800$ & $\sim 10 \%$ oxygen consumption \\
\hline 2-methylheptane & & & & \\
\hline $\begin{array}{l}\text { This study } \\
\text { 2,5-dimethylhexane }\end{array}$ & PetroOxy & $\mathbf{M H}+\mathbf{O}_{2}$ & $\sim 1000$ & $\sim 10 \%$ oxygen consumption \\
\hline $\begin{array}{l}\text { This study } \\
2,2,4 \text {-trimethylpentane }\end{array}$ & PetroOxy & $\mathrm{DMH}+\mathrm{O}_{2}$ & $\sim 1000$ & $\sim 10 \%$ oxygen consumption \\
\hline This study & PetroOxy & $\mathbf{T M P}+\mathrm{O}_{2}$ & $\sim 1000$ & $\sim 10 \%$ oxygen consumption \\
\hline Skolniak (2015) $)^{17}$ & PetroOxy & $\mathbf{T M P}+\mathrm{O}_{2}$ & $\sim 800$ & $\sim 10 \%$ oxygen consumption \\
\hline In models & $\begin{array}{l}\text { Homogeneous } \\
\text { reactor model }\end{array}$ & $\mathrm{iC}_{8}+\mathrm{O}_{2}$ & Exp. cond. & $5 \%$ fuel consumption \\
\hline
\end{tabular}

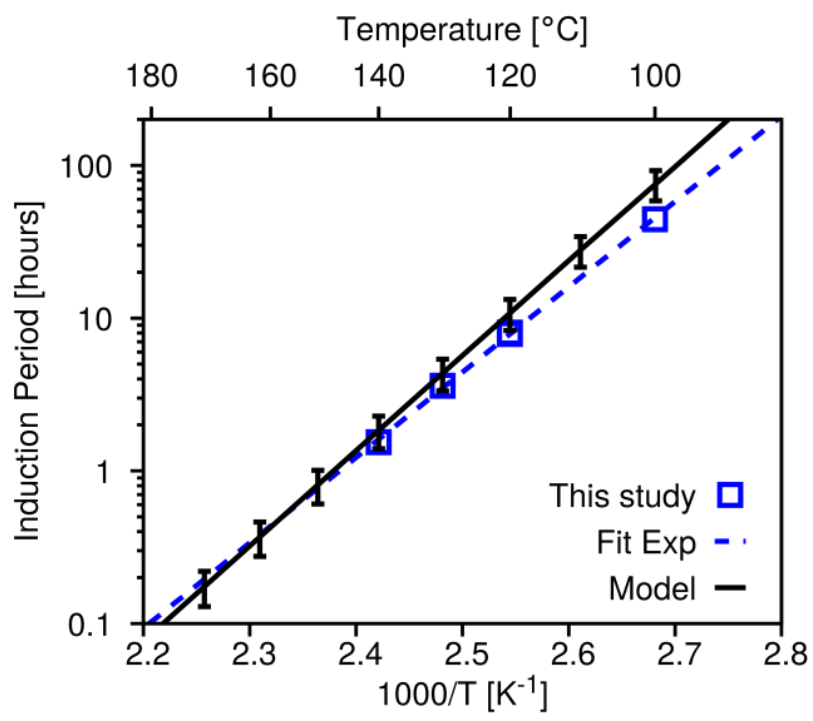

Figure 6: 2-Methylheptane model prediction on IP against present study (blue symbols) and literature data (black symbols). For clarity sake, a regression on present study data (dashed blue line) is performed to assess models (solid black lines) performance. Uncertainty bars represent the IP variation regarding to the oxygen dissolved into liquid. The minimum and maximum respectively corresponds to 5oppm and $2 \%$ of initial Oxygen.

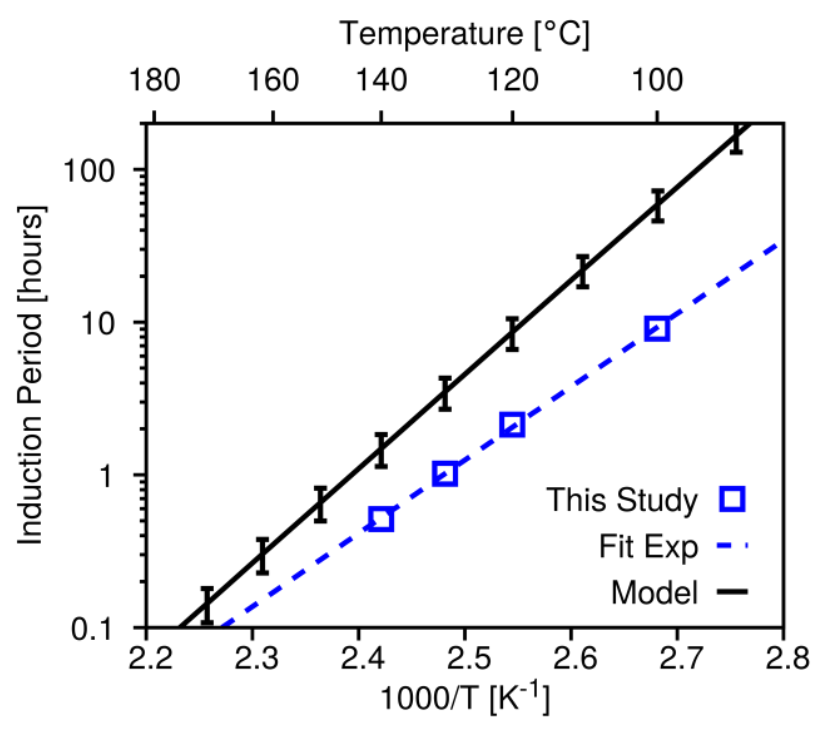

Figure 7: 2,5-dimethylhexane model prediction on IP against present study (blue symbols) and literature data (black symbols). For clarity sake, a regression on present study data (dashed blue line) is performed to assess models (solid black lines) performance. Uncertainty bars represent the IP variation regarding to the oxygen dissolved into liquid. The minimum and maximum respectively corresponds to 50ppm and $2 \%$ of initial Oxygen. 


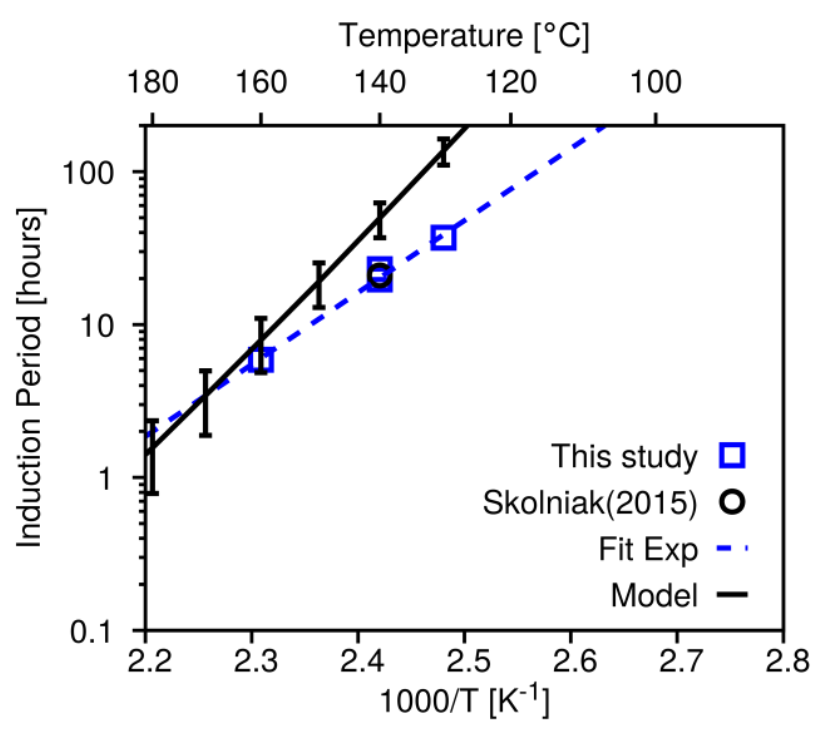

Figure 8: 2,2,4-trimethylpentane model prediction on IP against present study (blue symbols) and literature data (black symbols). For clarity sake, a regression on present study data (dashed blue line) is performed on the high temperature regime only to assess models (solid black lines) performance. Uncertainty bars represent the IP variation regarding to the oxygen dissolved into liquid. The minimum and maximum respectively corresponds to 5oppm and $2 \%$ of initial Oxygen.

Focusing on the model predictions, MH mechanism shows the best agreement with experimental data over the range 373-433 K, predicting IPs below a factor of 2. MH and TMP mechanisms are still able to predict IP within a factor of 3 at high temperature $(\mathrm{T}>403 \mathrm{~K})$. A similar agreement is obtained only at higher temperature $(\mathrm{T}>423 \mathrm{~K})$ for $\mathrm{C}_{8}$ and $\mathrm{DMH}$. For the low-temperature range $(\mathrm{T}<373 \mathrm{~K})$, models tend to over-predict IP by higher than a factor of 5 and 10 respectively for $\mathrm{DMH}$ and both $\mathrm{n}-\mathrm{C}_{8}$ and TMP.

\section{Branching effect}

Figure 9 and Figure 10 present models capabilities to reproduce the branching effect observed over the molecule tested at 393 and $413 \mathrm{~K}$. While models prediction could still be improved quantitatively, they qualitatively capture correctly the branching effect over all the conditions tested. While the impact of the first branching is well predicted by models, the second branching effect turns out to be highly underestimated. This underestimation might be due to the high symmetry of DMH: (i) due to specific intra-molecular reaction of $\mathrm{DMH}$ or (ii) due to the enhancement of specific kinetic rates poorly estimated by RMG.

To summarize the overall agreement, Figure 11 presents the relative errors (RE) made by predicting IPs at several temperatures. The $n-C_{8}$ mechanism from literature ${ }^{12}$ shows a slightly better agreement than its extended version presented in this section. Figure 11 sticks to previous observations identifying (i) $\mathrm{MH}$ models with the best predictions and (ii) all others models overestimates IPs below a factor of 4 for high temperature (for $\mathrm{T}>403 \mathrm{~K}$ and $423 \mathrm{~K}$ respectively for TMP and both $\mathrm{n}-\mathrm{C}_{8}$ and $\mathrm{DMH}$ ). The present models only involve pure compound oxidation, part of the remaining discrepancies could be associated with the catalytic effect of the $1 \%$ impurities that are not considered in our mechanisms. These effects could be even more important in the case of non-linear blending effects ${ }^{22}$. The next section aims at presenting rate analysis (Rate of Production (RoP)/Rate of Consumption (RoC)) to assess the impact of paraffin branching on autoxidation mechanism.

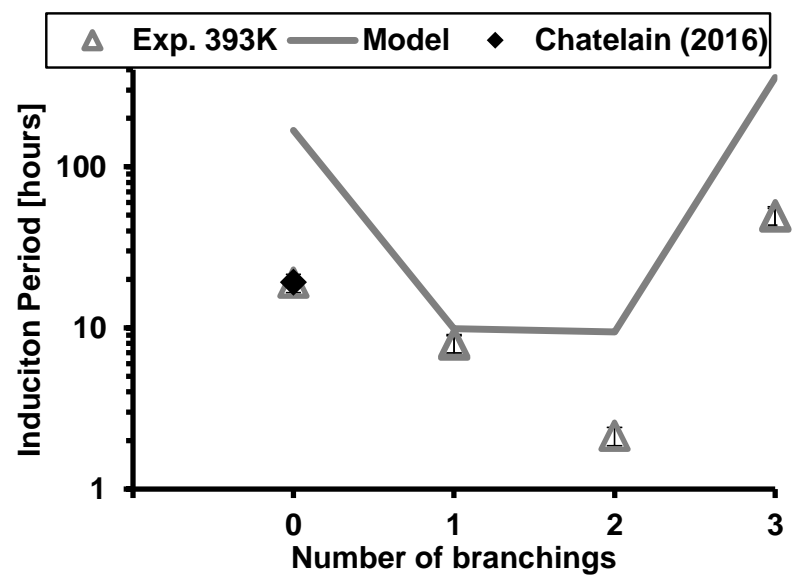

Figure 9: Models prediction of the branching impact on paraffins oxidation kinetics at $393 \mathrm{~K}$.

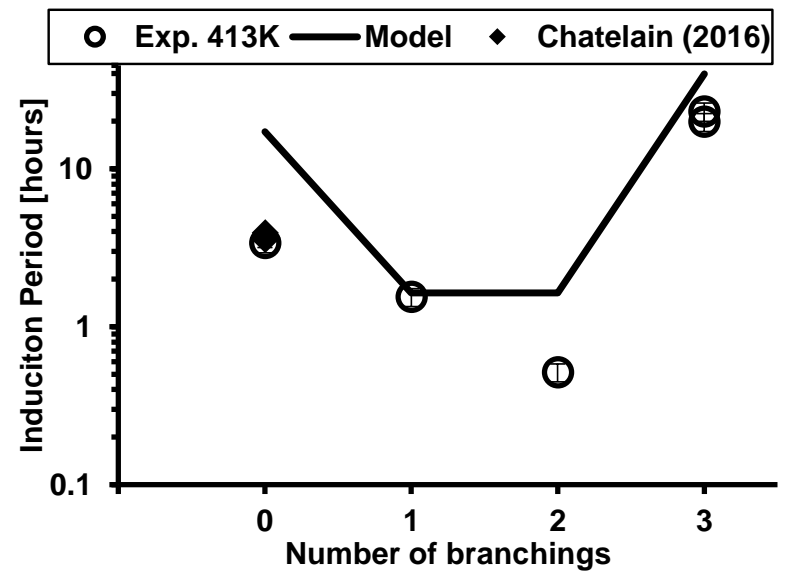

Figure 10: Models prediction of the branching impact on paraffins oxidation kinetics at $413 \mathrm{~K}$ 


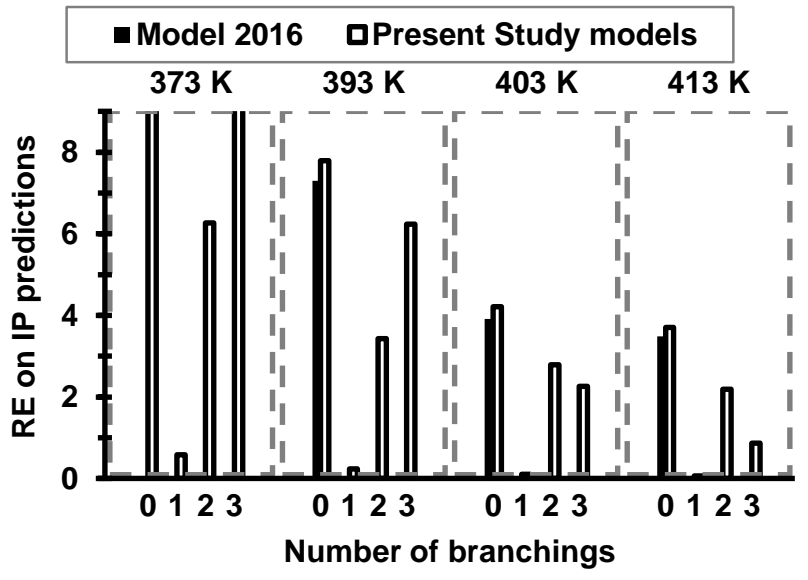

Figure 11: Relative Errors (RE) for both present and literature data models to predict the Induction Periods (IP) at several temperatures. Models with o and 3 branchings at $373 \mathrm{~K}$ are out of the scale and respectively have a RE of 24 and 47.

\section{Mechanism analyses}

To better characterize each mechanism, analyses were performed with two oxygen concentrations on (i) global reactivity, (ii) RoP/RoC distribution and (iii) major species profiles. Finally, a sensitivity analysis of IP with respect to the kinetics of different reaction families was performed to assess the most important reaction pathways involved in branched alkanes autoxidation. The two oxygen concentrations selected aim at representing the reactivity difference between highly and poorly oxygenated media $(\times 20$ on $\mathrm{O}_{2}$ concentration) respectively presented in dashed and solid lines. These two extreme conditions aim also to identify the effect of local oxygen concentration inhomogeneity due to fast reaction rates (locally). Only the figures evidencing the major trends observed are presented in this section and all figures generated for each mechanism are presented separately as a supporting information.

\section{Consumption paths comparison}

As the global reactivity are similar for the selected paraffins, $C_{8}$ mechanism is selected to represent the alkane autoxidation. The global reactivity is defined as the sum of absolute values of RoC/RoP and is presented in Figure 12 for $C_{8}$ at three different temperatures and two oxygen concentrations. First, the increase of temperature induces both an increase of the RoC/RoP maximum values and a decrease of the corresponding time required to reach this maximum. This modeling result is consistent with the decrease of IP with increasing temperature. Although oxygen concentration quantitatively influences the sum of RoC and RoP, the overall trend remains similar with the three

1 Due to similarities between $\mathrm{MH}$ and DMH RoC, DMH result is presented in supplementary materials. temperature investigated. This poor effect of oxygen concentration, where profiles remain qualitatively similar, is also observed with the sum of RoC/RoP on both $\mathrm{OH}^{\circ}$ and $\mathrm{HO}_{2}^{\circ}$ radicals (cf. supplementary data).

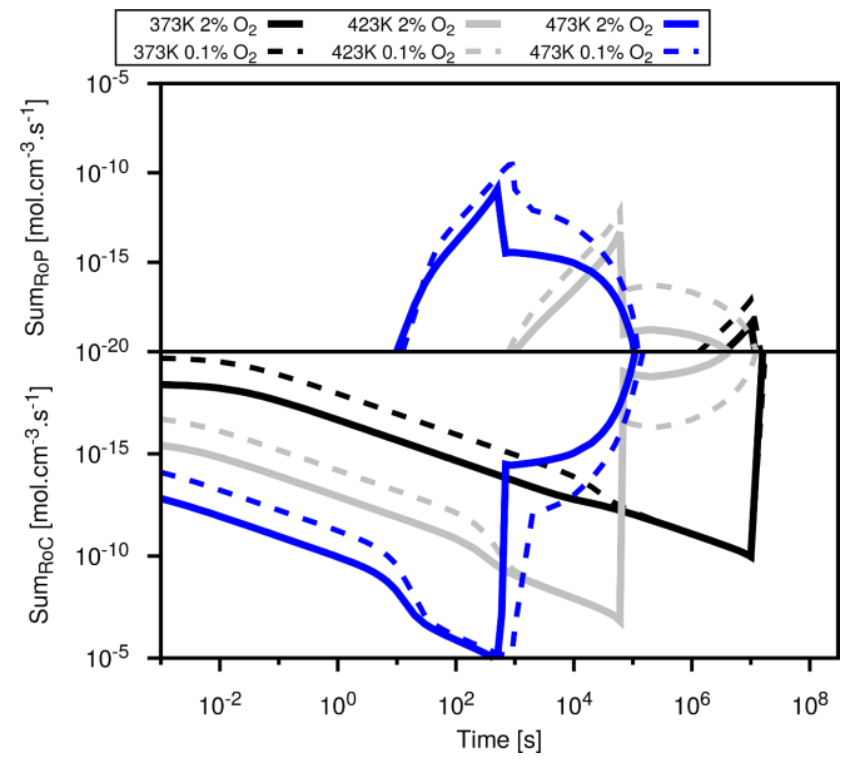

Figure 12: Sum of $R o C / R o P$ on fuel consumption for the $C 8$ mechanism at $373 \mathrm{~K}, 423 \mathrm{~K}$ and $473 \mathrm{~K}$.

Concerning the RoP/RoC distribution, as there are more than five orders of magnitude difference, only RoC distribution is presented. RoC analyses are performed at $423 \mathrm{~K}$ only where the agreement is optimal and due to the poor temperature sensibility observed in Figure 12. Except for the early stage of oxidation $\left(\mathrm{t} / \mathrm{IP}<10^{-6}\right)$ during which $\mathrm{O}_{2}$ and $\mathrm{HO}_{2}$ mostly contribute to the fuel consumption, the major consumption pathway (> $95 \%$ contribution) relies on the $\mathrm{ROO}^{\circ}$ and $\mathrm{HOOQOO}^{\circ}$ radicals until the fuel conversion is reached $(\mathrm{t} / \mathrm{IP}>\mathbf{2})$ for the four octane isomers. Focusing on minor paths, the $\mathrm{HO}_{2}$ contribution is different between C8 \& TMP and MH \& $\mathrm{DMH}^{1}$. In $\mathrm{MH}$ and $\mathrm{DMH}$ mechanisms, $\mathrm{HO}_{2}$ contribution follows oxygen's one by dropping rapidly after initiation, while its contribution remains at the percent level during the whole propagation stage for C8 \& TMP. Similarly, OH contribution is increasing rapidly close to IP ( $t /$ IP > o.1) for both C8 \& TMP until reaching a fraction of o.1, while in $\mathrm{MH}$ and $\mathrm{DMH}, \mathrm{OH}$ contribution reaches a peak after IP and represents less than $1 \%$.

Similarly to the global reactivity presented in Figure 12, oxygen concentration has a limited influence on the RoC distribution for both $\mathrm{MH}$ and DMH oxidation while small differences are observed with C8 (Figure 13) and TMP mechanism (Figure 14). Indeed, in the case of $\mathrm{MH}$ and $\mathrm{DMH}$, the 
oxygen induces a contribution change between $\mathrm{HOOQOO}^{\circ}$ and $\mathrm{ROO}^{\circ}$. They respectively increase and decrease to reach $\approx 50 \%$ of the total rate during the propagation step $\left(10^{-6} \leq \mathrm{t} / \mathrm{IP} \leq 10^{-2}\right)$. Finally, TMP has a very specific RoC distribution compared to the three others isoalkane and is presented in Figure 15. First, the reactions involving secondary hydroperoxides seem to contribute only at IP. Also, $\mathrm{H}$ abstraction by peroxy radicals is the main consumption path after a quick initiation time $\left(t<10^{-6}\right)$ and (iii) a new reaction family seems to contribute to a minor extent $(<1 \%)$ within a very sharp contribution range $(0.1<\mathrm{t} / \mathrm{IP}<1)$. This specific HOOQOO ${ }^{\circ}$ contribution is explainable by the small number of possible $\mathrm{HOOQOO}^{\circ}$ isomers on TMP compared with the possible $\mathrm{ROO}^{\circ}$.

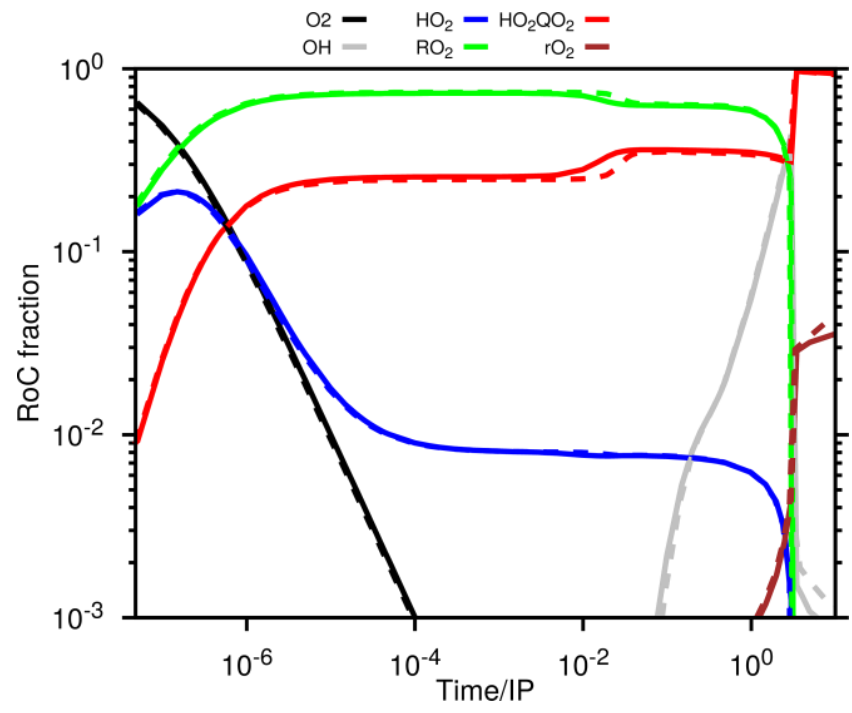

Figure 13: Effect of oxygen concentration on fuel RoC distribution for C8 model. This analysis is conducted at $423 \mathrm{~K}$ with $2 \%$ and 1000 ppm of oxygen respectively in solid and dashed lines.

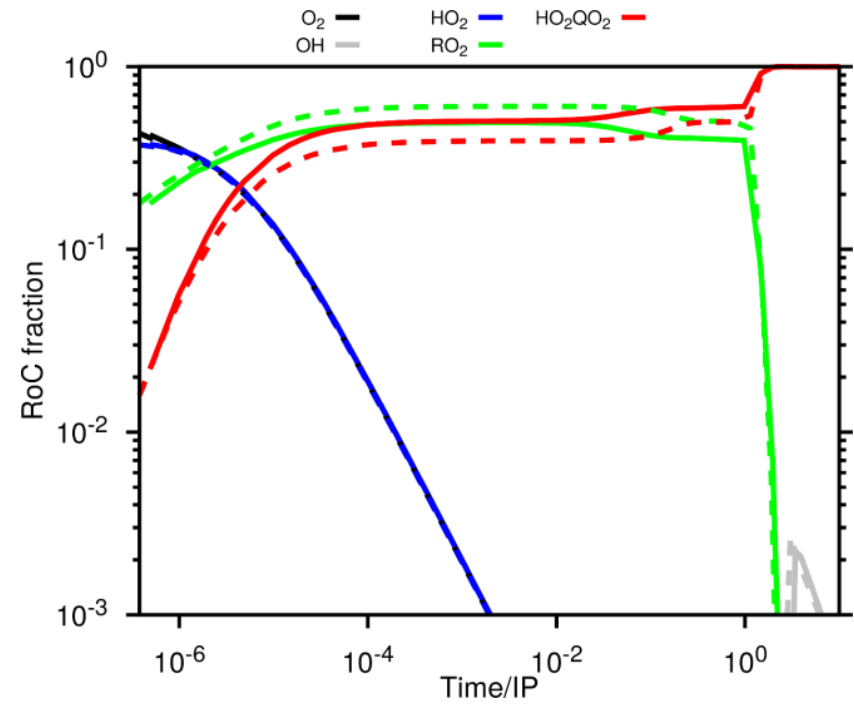

Figure 14: Effect of oxygen concentration on fuel RoC distribution for MH model. This analysis is conducted at $423 \mathrm{~K}$ with $2 \%$ and $1000 \mathrm{ppm}$ of oxygen respectively in solid and dashed lines. $r O O^{\circ}$ stands for the sum of light hydroperoxides from $C_{1}$ to $C_{7}$

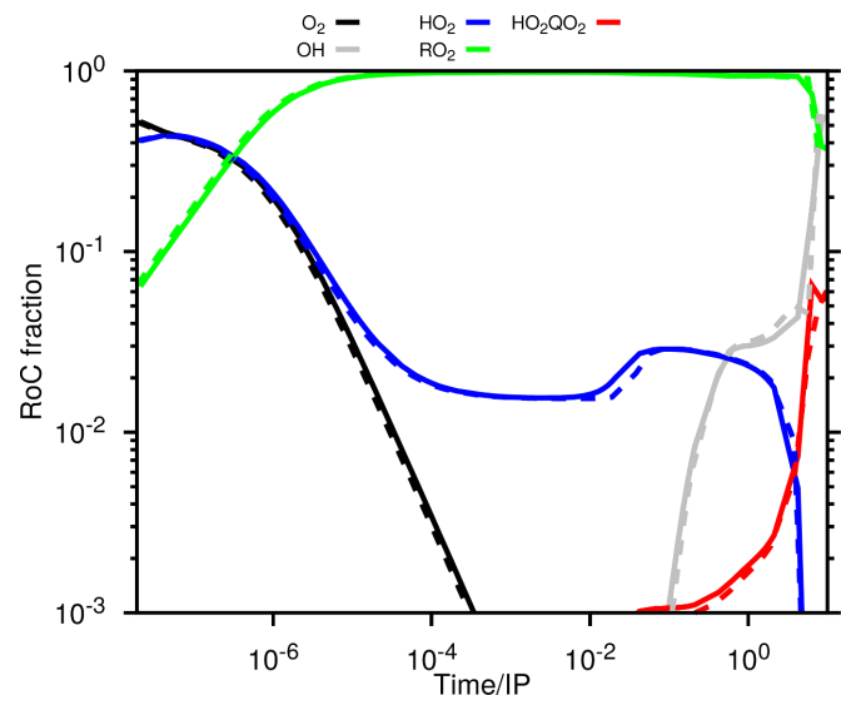

Figure 15: Effect of oxygen concentration on fuel RoC distribution for TMP model. This analysis is conducted at $423 \mathrm{~K}$ with $2 \%$ and $1000 \mathrm{ppm}$ of oxygen respectively in solid and dashed lines.

\section{Major oxidation products}

Species profiles predicted with the 4 mechanisms are presented in supplementary materials. Qualitatively, the species profiles are consistent with experimental observations, with mainly the formation of hydroperoxides and secondly the formation of ketones and alcohols before IP. The isomers distinction is observed for all lumped species and branching ratios are qualitatively in agreement with literature. While, the model reproduces the acid formation with several chain length, the total fraction of acids seems underestimated in all mechanisms. The Korcek's reactions are the main pathway contributing to the light carbonyl formation and no alternative pathways like the $\alpha / \beta C-C$ scission seem to be significant in the present conditions.

\section{Sensibility analyses}

A brute force sensitivity analysis is performed with the C8 model using the most contributing reactions to the fuel consumption. This is carried out by applying an enhancement factor $(\alpha)$ on the pre-exponential factor (A) on specific sets of reactions $\left(A^{\prime \prime}=A \times \alpha\right)$.

Figure 16 represents the relative IP variation as a function of two enhancement factors (o.9 and 1.1) for each set of reactions represented in Figure 16. For a first set of reaction family $\left(\mathrm{H}, \mathrm{HO}_{2}, \mathrm{HO}_{2} \mathrm{Q}, \mathrm{O}_{2}, \mathrm{OH}, \mathrm{RO}\right)$, IP seems fairly not sensitive to the $10 \%$ reaction rate change and presents a small IP variation $\left(\Delta I P \lesssim 1 \% I P_{i n i}\right)$. For both $\alpha$ values, the IP decreases for all these reaction families. For the second set of reaction family $\left(\mathrm{ROO}^{\circ}\right.$ and $\mathrm{HOOQOO}^{\circ}$ ), IP is more sensitive to the $10 \%$ variation and an absolute IP variation up to $7 \%$ and $4 \%$ is respectively observed. Also the IP variation is directly correlated to the reaction rate increase or decrease.

These results are consistent with the RoC analyses and confirm that the IP is highly dependent on the reactions of 
formation of mono and poly-hydroperoxides. Thus, small error on the thermokinetic data associated to these specific reactions may impact strongly modeling results.

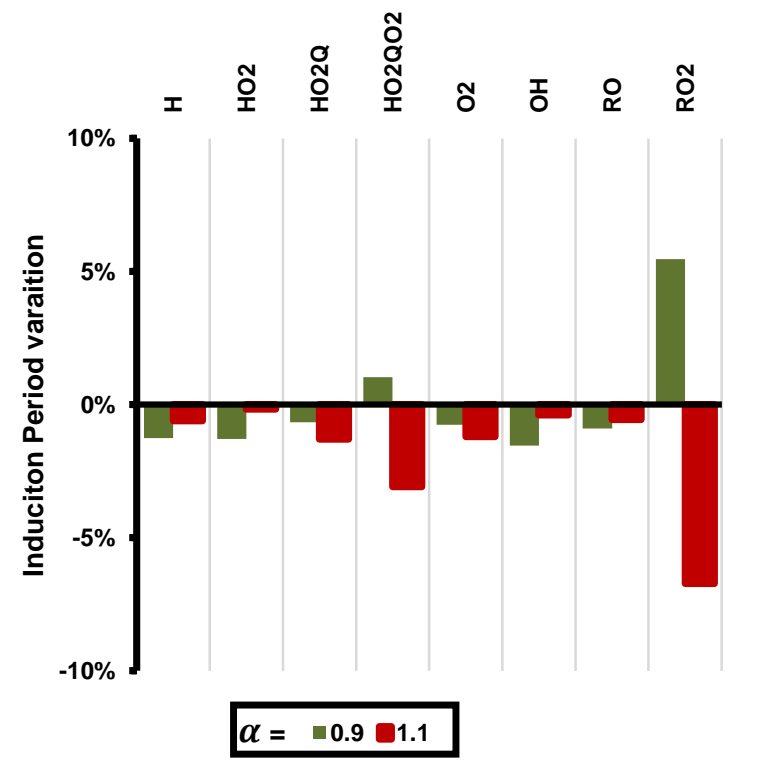

Figure 16 : Relative IP variation according to a specific enhancement factor $(\alpha)$ for a given reaction family. A 10\% variation of the initial pre-exponential factor was applied on the followingeight "fuel $+X$ " reaction families with $\mathrm{X}=\mathrm{H}^{\circ}, \mathrm{HO}_{2}^{\circ}$, $\mathrm{HO}_{2} \mathrm{Q}^{\circ}, \mathrm{HO}_{2} \mathrm{QO}_{2}^{\circ}, \mathrm{O}_{2}, \mathrm{OH}^{\circ}, \mathrm{RO}^{\circ}, \mathrm{RO}_{2}^{\circ}$.

\section{Quantifying structure-reactivity relations}

Based on current and previous results, structure-reactivity relations are assessed with both experimental and modeling approaches.

From literature and present experimental results, an empirical relationship based on Arrhenius expression $\left(I P_{\text {alkanes }}=A_{\text {alkanes }}^{\prime} \times \exp \left(\frac{T a_{\text {alkanes }}^{\prime}}{T}\right)\right)$ is established to describe paraffins reactivity using simple molecule descriptors (the number of carbon atoms and the carbon type) for $C_{8}-C_{16}$ alkanes between 393 and $433 \mathrm{~K}$. A linear dependence of $\ln \mathrm{A}^{\prime}$ and $\mathrm{Ta}$ ' (with Ta'=Ea'/R') with respect to the number of carbons as well as a quadratic dependence on the number of tertiary carbons (Figure 17) can be highlighted. The parameters for each compound are summarized in

Table 4. A similar enthalpy-entropy compensation effect ${ }^{47}$, which was discussed for $n$-alkanes ${ }^{12}$, may be identified on $\mathrm{C} 8, \mathrm{MH}$ and $\mathrm{DMH}$ results with respect to the number of tertiary carbons.

2 Additional comparison are available in supplementary materials: C8/DMH, C8/TMP and MH/TMP.
In most of conditions with IPs below 72 hours, this correlation is able to reproduce all experiments within an error range comparable to the sum of experimental measurements uncertainties (20\%). A typical validation case is presented in Figure 17.

Table 4: Summary of all parameters used for the establishment of the empirical correlation. $M H, D M H, T M P$ respectively stand for 2-methylheptane, 2,5-dimethylhexane and 2,2,4-trimethylpentane.

\begin{tabular}{l|c|c|} 
Compound & $A^{\prime}[\mathrm{h}]$ & $\mathrm{Ta}[\mathrm{K}]$ \\
\hline \hline$n-C_{8}$ & $3.627 \times 10^{-14}$ & 13.35 \\
$n-C_{10}$ & $1.829 \times 10^{-14}$ & 13.51 \\
$n-C_{12}$ & $7.301 \times 10^{-15}$ & 13.84 \\
$n-C_{14}$ & $2.873 \times 10^{-15}$ & 14.19 \\
$n-C_{16}$ & $1.202 \times 10^{-14}$ & 13.54 \\
$M H$ & $2.664 \times 10^{-13}$ & 12.52 \\
$D M H$ & $4.721 \times 10^{-14}$ & 12.87 \\
$T M P$ & $1.245 \times 10^{-12}$ & 11.06
\end{tabular}
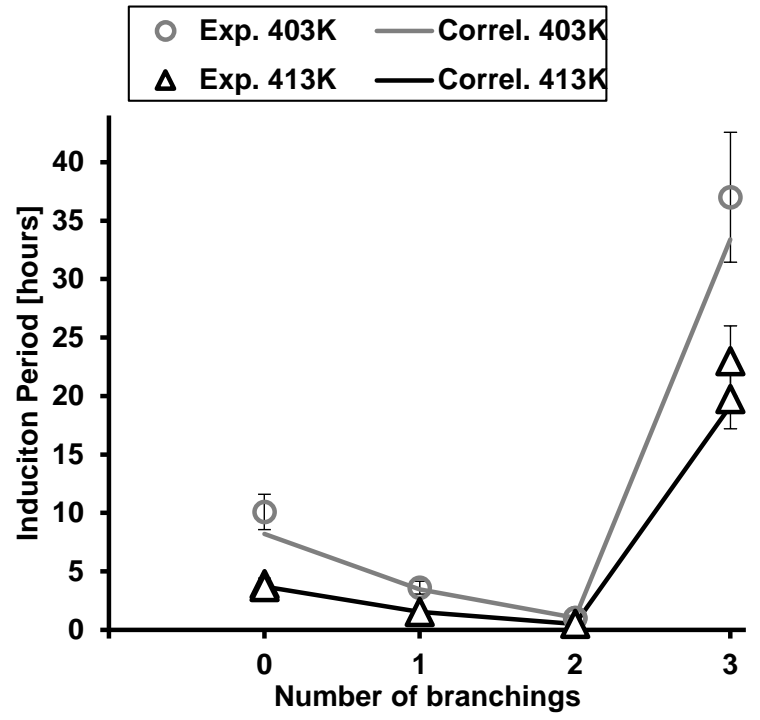

Figure 17: Agreement of correlation prediction with experimental results for both normal and iso-paraffins at two different temperatures. Complementary cases are provided in the supporting material.

To better understand the origin of reactivity difference among alkanes, we studied the evolution of the absolute $\mathrm{RoC}$ for both $\mathrm{C}_{8}$ (solid lines) and $\mathrm{MH}$ (dashed lines) at $423 \mathrm{~K}^{2}$ (Figure 18). While the fuel RoC distribution of both compounds are similar, significant changes may be observed by comparing the temporal evolution of their absolute values. These differences emphasizes that their autoxidation kinetics are dependent of their chemical structures.

Thus, except from the $\mathrm{OH}$ reaction family, we can identify the following structure-reactivity relations from the kinetic 
rate parameters presented in Table 5: (i) the Ea of the listed $\mathrm{H}$-abstraction reactions is the lowest when the Hydrogen is abstracted from a tertiary carbon and it is the highest when it is abstracted from a primary carbon; (ii) Ea of reactions involving peroxy radicals from a tertiary carbon have an higher Ea compare to peroxy radicals from a primary and secondary carbon.

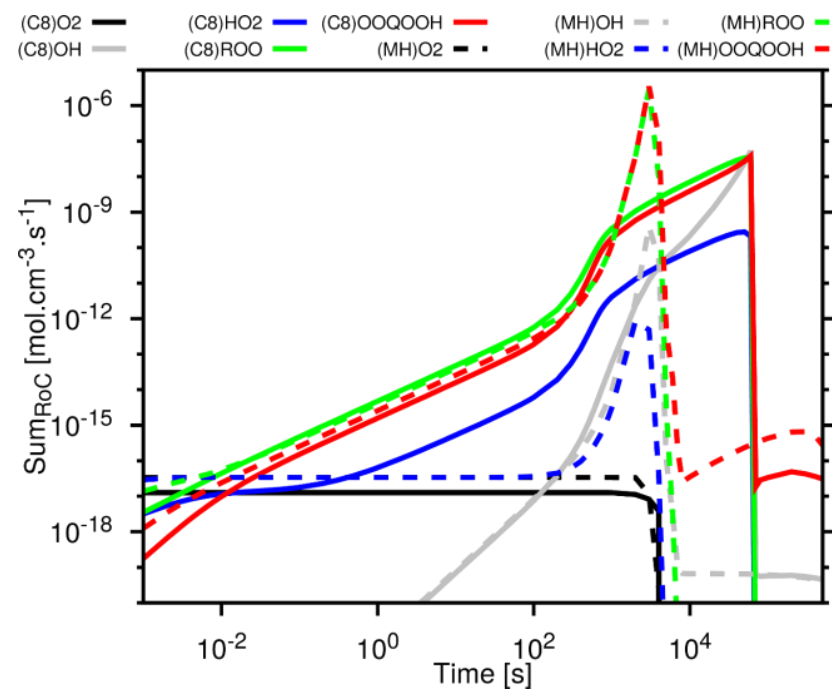

Figure 18: Temporal evolution of the sum of RoC per chemical families at $423 \mathrm{~K}$ between $\mathrm{C} 8$ and $\mathrm{MH}$ respectively in solid and dashed lines.

Figure 20 confirms these statements and presents that the kinetic rate increases by 2 orders of magnitude from primary to secondary or from secondary to tertiary hydrogen atoms. This second value is in agreement with literature ${ }^{28,48}$. Thus, the specific reactivity of TMP compared to others $\mathrm{iC}_{8}$ may be explained by the abundance of primary hydrogen atoms.

Cartensen et al.49 presented different rate constants for $\mathrm{ROO}+\mathrm{C}_{2} \mathrm{H}_{6}$ gas-phase reaction with $\mathrm{R}=\left[\mathrm{H}, \mathrm{CH}_{3}, \mathrm{C}_{2} \mathrm{H}_{6}\right]$ and thereby predicted a slight decrease of the rate constant ( < $\mathbf{2 5} \%$ ) in the low temperature region $300-500 \mathrm{~K}$ with $\mathrm{R}(\mathrm{II}) \mathrm{OO}<\mathrm{R}(\mathrm{I}) \mathrm{OO}$. This finding pleads for the implementation of structure-dependent rate data for higher alkanes to improve further the rate rules. As presented in Table 5, the present mechanisms do not consider selectivity between these two peroxy radicals. In addition, the absence of differences in the kinetic rates of $\mathrm{ROO}$ and HOOQOO reactions was unexpected and the rate rules definitions for these specific reactions may require improvements.

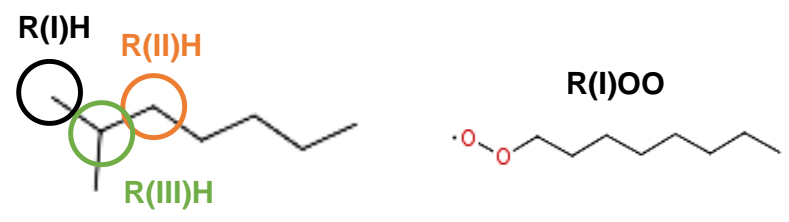

Figure 19: Carbon type representation used to identify reacting sites.

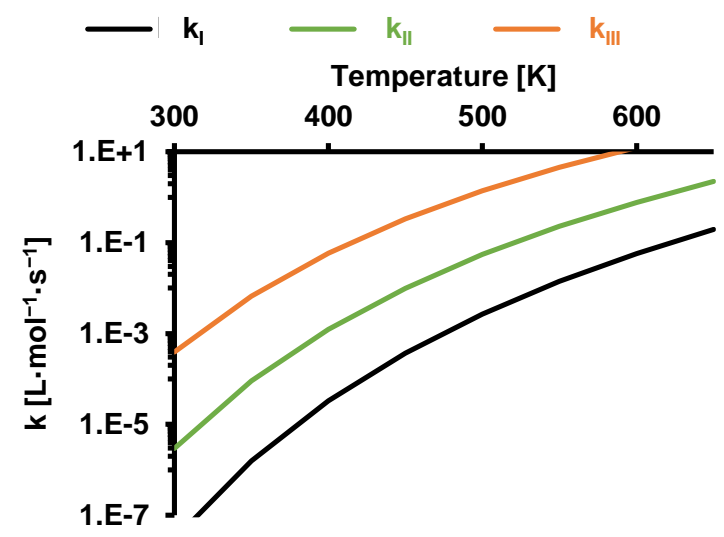

Figure 20: The three different rate constants of the reaction $R H$ $+R O O^{\circ} \rightleftarrows R^{\circ}+R O O H$ as function of the three different types of hydrogen atoms. 
Table 5: Kinetic parameters of reactions involved in the RoC analysis of fuel. I, II and III illustrate the rate constant distinction if the radical on $R^{\circ}$ is respectively on a primary, secondary and tertiary carbon. "pri","sec", "tert." aims at differentiating the carbons holding a given chemical function (e.g: $R O O^{\circ}$ pri refers to a peroxy radical which is on a primary carbon).

\begin{tabular}{|c|c|c|c|}
\hline Reaction labels & $\mathrm{A}\left[\mathrm{mol} \cdot \mathrm{cm}^{-3} \cdot \mathrm{s}^{-1}\right]$ & $\mathbf{n}$ & Ea $\left[\right.$ kcal.mol $\left.{ }^{-1}\right]$ \\
\hline \multicolumn{4}{|l|}{ 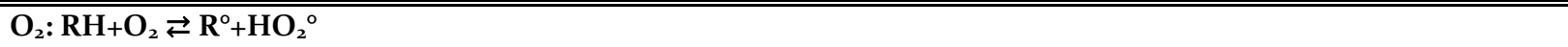 } \\
\hline (I): C8 & $2.49 \times 10^{12}$ & -0.34 & 45.0 \\
\hline (I): MH \& TMP & $3.54 \times 10^{11}$ & -0.18 & 44.0 \\
\hline (I): MH & $1.08 \times 10^{12}$ & -0.34 & 45.0 \\
\hline (I): DMH & $7.07 \times 10^{11}$ & -0.18 & 44.0 \\
\hline (I): TMP & $1.14 \times 10^{13}$ & -0.48 & 45.0 \\
\hline (II): C8 & $5.08 \times 10^{13}$ & -0.69 & 42.0 \\
\hline (II): MH & $2.21 \times 10^{13}$ & -0.69 & 42.0 \\
\hline (II): MH & $6.53 \times 10^{13}$ & -0.86 & 42.0 \\
\hline (II): C8 & $1.50 \times 10^{14}$ & -0.86 & 42.0 \\
\hline (II): MH \& TMP & $1.95 \times 10^{13}$ & -0.69 & 42.0 \\
\hline (II): DMH & $3.89 \times 10^{13}$ & -0.69 & 42.0 \\
\hline (III): MH \& TMP & $1.38 \times 10^{14}$ & -0.99 & 41.0 \\
\hline (III):DMH & $2.76 \times 10^{14}$ & -0.99 & 41.0 \\
\hline \multicolumn{4}{|c|}{$\mathrm{OH}^{\circ}: \mathrm{RH}+\mathrm{OH} \rightleftarrows \mathrm{R}^{\circ}+\mathrm{H}_{2} \mathrm{O}$} \\
\hline (I): C8 \& MH \& TMP & $7.20 \times 10^{6}$ & 2.00 & 0.86 \\
\hline (I): MH & $3.60 \times 10^{6}$ & 2.00 & 0.86 \\
\hline (I): DMH & $1.44 \times 10^{7}$ & 2.00 & 0.86 \\
\hline (I): TMP & $1.08 \times 10^{7}$ & 2.00 & 0.86 \\
\hline (II) : C8 \& DMH & $1.58 \times 10^{6}$ & 1.90 & 0.16 \\
\hline (II) : MH \& TMP & $7.90 \times 10^{6}$ & 1.90 & 0.16 \\
\hline (III) : DMH & $5.14 \times 10^{6}$ & 1.90 & 1.45 \\
\hline (III) : TMP & $2.57 \times 10^{6}$ & 1.90 & 1.45 \\
\hline \multicolumn{4}{|c|}{$\mathrm{HO}_{2}^{\circ}: \mathrm{RH}+\mathrm{HO}_{2}^{\circ} \rightleftarrows \mathrm{R}^{\circ}+\mathrm{H}_{2} \mathrm{O}_{2}$} \\
\hline (I) $\mathrm{C} 8$ & $1.50 \times 10^{2}$ & 3.17 & 15.0 \\
\hline (I) MH \& TMP & $2.44 \times 10^{1}$ & 3.33 & 15.0 \\
\hline (I) $\mathrm{MH}$ & $7.48 \times 10^{1}$ & 3.17 & 15.0 \\
\hline (I) DMH & $4.89 \times 10^{1}$ & $3 \cdot 33$ & 15.0 \\
\hline (I) TMP & $7.86 \times 10^{2}$ & 3.03 & 15.0 \\
\hline (II) C8 & $1.71 \times 10^{3}$ & 2.80 & 12.0 \\
\hline (II) $\mathrm{C8}$ & $5.07 \times 10^{3}$ & 2.63 & 12.0 \\
\hline (II) MH \& TMP & $7.56 \times 10^{2}$ & 2.80 & 12.0 \\
\hline (II) MH & $2.54 \times 10^{3}$ & 2.63 & 12.0 \\
\hline (II) $\mathrm{MH}$ & $8.56 \times 10^{2}$ & 2.80 & 12.0 \\
\hline (II) $\mathrm{DMH}$ & $1.51 \times 10^{3}$ & 2.80 & 12.0 \\
\hline (III) MH \& TMP & $1.62 \times 10^{5}$ & 2.27 & 11.0 \\
\hline (III) DMH & $3.25 \times 10^{5}$ & 2.27 & 11.0 \\
\hline \multicolumn{4}{|c|}{$\mathrm{RO}_{2}^{\circ} \& \mathrm{HO}_{2} \mathrm{QO}_{2}^{\circ}$ pri. \& sec. } \\
\hline (I) MH \& TMP & $7.45 \times 10^{-2}$ & 3.95 & 14.0 \\
\hline (I) $\mathrm{MH}$ & $2.28 \times 10^{-1}$ & 3.79 & 14.0 \\
\hline (I) $\mathrm{C} 8$ & $4.56 \times 10^{-1}$ & 3.79 & 14.0 \\
\hline (I) DMH & $1.49 \times 10^{-1}$ & 3.95 & 14.0 \\
\hline (I) TMP & $2.39 \times 10^{\circ}$ & 3.65 & 14.0 \\
\hline (II) MH \& TMP & $3.72 \times 10^{\circ}$ & 3.49 & 12.0 \\
\hline (II) $\mathrm{DMH}$ & $7.43 \times 10^{\circ}$ & 3.49 & 12.0 \\
\hline (II) $\mathrm{C8}$ & $2.49 \times 10^{1}$ & 3.49 & 11.0 \\
\hline (II) MH & $1.25 \times 10^{1}$ & $3 \cdot 32$ & 11.0 \\
\hline (II) $\mathrm{C8}$ & $8.42 \times 10^{1}$ & 3.49 & 11.0 \\
\hline (II) $\mathrm{MH}$ & $4.21 \times 10^{\circ}$ & 3.49 & 11.0 \\
\hline (III) MH \& TMP & $4.95 \times 10^{2}$ & 2.90 & 10.0 \\
\hline (III) DMH & $9.89 \times 10^{2}$ & 2.90 & 10.0 \\
\hline \multicolumn{4}{|l|}{$\mathrm{RO}_{2}^{\circ} \& \mathrm{HO}_{2} \mathrm{QO}_{2}{ }^{\circ}$ tert. } \\
\hline (I) MH \& TMP & $7 \cdot 45 \times 10^{-2}$ & 3.95 & 17.0 \\
\hline (I) DMH & $1.49 \times 10^{-1}$ & 3.95 & 17.0 \\
\hline (I) $\mathrm{MH}$ & $2.28 \times 10^{-1}$ & 3.79 & 17.0 \\
\hline (I) TMP & $2.39 \times 10^{\circ}$ & 3.65 & 17.0 \\
\hline (II) MH \& TMP & $3.72 \times 10^{\circ}$ & 3.49 & 14.0 \\
\hline (II) $\mathrm{DMH}$ & $7 \cdot 43 \times 10^{\circ}$ & 3.49 & 14.0 \\
\hline (II) MH & $1.25 \times 10^{1}$ & $3 \cdot 32$ & 14.0 \\
\hline (II) $\mathrm{MH}$ & $4.21 \times 10^{\circ}$ & 3.49 & 14.0 \\
\hline (III) MH \& TMP & $4.95 \times 10^{2}$ & 2.90 & 13.0 \\
\hline (III) DMH & $9.89 \times 10^{2}$ & 2.90 & 13.0 \\
\hline
\end{tabular}




\section{CONCLUSIONS}

This experimental and modeling work is focused on the autoxidation of four isooctanes: n-octane (C8), 2-methylheptane (MH), 2,5-dimethylhexane (DMH) and the 2,2,4-trimethylpentane (TMP). Experimentally, each compound reactivity was assessed using the PetroOxy device and their inherent major oxidation products were identified by analyzing liquid residuals with a GC-MS. Thus, omitting the specific reactivity of TMP, the isoalkanes stability was found to exponentially decrease with the number of branchings under the experimental conditions investigated. However, experimental results for TMP oxidation indicate an IP increase compared to $C_{8}$ results and are in agreement with literature data ${ }^{17}$. The GC-MS analyses revealed similar oxidation products with different distributions resulting from the molecule symmetry.

Detailed liquid phase models were developed for each alkane using the RMG mechanism generator. Considering current modeling limitations of the liquid phase, the models reproduce fairly well the temperature dependence of stability while the branching effect remains less correctly captured by models for $\mathrm{C}_{8}$ and $\mathrm{DMH}$. RoP and sensitivity analyses demonstrated that fuel consumption reactions involving ROO and HOOQOO radicals constitute the major consumption pathways. Thus, the quantitative predictions of the present models may be significantly improved by refining some rate rules implemented in RMG, notably considering the third $\mathrm{O}_{2}$ addition ${ }^{50}$ or the selectivity of the peroxy rate rules. In addition, a better representation of the solvent effect, notably on the kinetic, may significantly improve mechanisms predictability and selectivity as presented on literature ${ }^{51,52}$.

Concerning the structure-reactivity relation claimed by Skolniak et $\mathrm{al}^{17}$, the present work demonstrated that the increase of branching does not necessary increase fuel stability. As presented in both experimental and modeling results, isoalkanes reactivity is correlated to the carbon type available on the molecule: primary, secondary, tertiary and quaternary. According to the present model, these observations can be explained by the impact of the type of $\mathrm{H} \mathrm{ab}$ stracted on the kinetic rate constant of $\mathrm{RH}+\mathrm{ROO}$ reaction.

Finally, this work proposes an original correlation to estimates isoalkanes reactivity as function of a very limited set of descriptors: chain length and carbon types in fuel. Further experimental work on others isoparaffins is required to improve the proposed correlation by introducing more advanced topological descriptors accounting for the impact of the mutual branching distances on reactivity or stability. Another perspective would be to study the stability of blends involving normal and branched paraffins to identify potential non-linear blending effects than may occur in real fuels. All these aspects are being currently investigated in our group and will greatly contribute to the development of QSPR models to predict fuel stability.

\section{ACKNOWLEDGMENTS}

This work was funded by IFPEn and ENSTA ParisTech in collaboration with several IFPEn divisions. We acknowledge Mr. Hayrault from the analytical division for providing the GC-MS operated during this study. We are thankful to experimental division, Mr. Veyrat and Mrs Horlaville for respectively providing and operating the PetroOxy.

In addition, we are thankful to Pr. Green, Pr. West and the whole RMG team for providing the present RMG version and for our fruitful discussions.

\section{ASSOCIATED CONTENT}

Supporting Information. All mechanisms and all experimental data obtained in the present work as well as additional details on mechanism validation are available as supporting information.

\section{AUTHOR INFORMATION}

\section{Corresponding Author}

*E-mail: karl.chatelain@gmail.com

\section{ABBREVIATIONS}

LPA, Liquid Phase Autoxidation; LT, Low Temperature; GC, Gas Chromatography; MS, Mass Spectrometer; IP, Induction Period; RoP, Rate of Production; RoC, Rate of Consumption BDE, Bond Dissociation Energy; $\mathrm{n}-\mathrm{C}_{8}$ or C8, n-octane; $\mathrm{MH}$ : 2methylheptane; DMH: 2,5-dimethylhexane; TMP, 2,2,4-trimethylpentane.

\section{References}

(1) Yang, Z.; Hollebone, B. P.; Wang, Z.; Yang, C.; Brown, C.; Landriault, M. Storage stability of commercially available biodiesels and their blends under different storage conditions. Fuel 2014, 115, 366-377.

(2) Sem, T. R. Investigation of Injector Tip Deposits on Transport Refrigeration Units Running on Biodiesel Fuel, 2004.

(3) Marteau, C.; Ruyffelaere, F.; Aubry, J.-M.; Penverne, C.; Favier, D.; Nardello-Rataj, V. Oxidative degradation of fragrant aldehydes. Autoxidation by molecular oxygen. Tetrahedron 2013, 69, 2268-2275.

(4) Matsumoto, S.; Date, K.; Taguchi, T.; Herrmann, O. E. The New DENSO Common Rail Diesel Solenoid Injector. MTZ worldwide 2013, 74, 44-48.

(5) Doungthip, T.; Ervin, J. S.; Zabarnick, S.; Williams, T. F. Simulation of the effect of metal-surface catalysis on the thermal oxidation of jet fuel. Energy \& Fuels 2004, 18, 425-437.

(6) Ervin, J. S.; Zabarnick, S. Computational fluid dynamics simulations of jet fuel oxidation incorporating pseudodetailed chemical kinetics. Energy \& Fuels 1998, 12, 344352.

(7) Balster, L. M.; Corporan, E.; DeWitt, M. J.; Edwards, J. T.; Ervin, J. S.; Graham, J. L.; Lee, S.-Y.; Pal, S.; Phelps, D. K.; Rudnick, L. R. et al. Development of an advanced, 
thermally stable, coal-based jet fuel. Fuel Processing Technology 2008, 89, 364-378.

(8) Kuprowicz, N. J.; Zabarnick, S.; West, Z. J.; Ervin, J. S. Use of Measured Species Class Concentrations with Chemical Kinetic Modeling for the Prediction of Autoxidation and Deposition of Jet Fuels. Energy \& Fuels 2007, 21, 530-544.

(9) Zabarnick, S. Chemical kinetic modeling of jet fuel autoxidation and antioxidant chemistry. Industrial $\mathcal{E}$ engineering chemistry research 1993, 32, 1012-1017.

(10) Pfaendtner, J.; Broadbelt, L. J. Mechanistic Modeling of Lubricant Degradation. 2. The Autoxidation of Decane and Octane. Industrial E engineering chemistry research 2008, 47, 2897-2904.

(11) Ben Amara, A.; Nicolle, A.; Alves-Fortunato, M.; Jeuland, N. Toward Predictive Modeling of Petroleum and Biobased Fuel Stability: Kinetics of Methyl Oleate/n-Dodecane Autoxidation. Energy \& Fuels 2013, 27, 6125-6133. (12) Chatelain, K.; Nicolle, A.; Ben Amara, A.; Catoire, L.; Starck, L. Wide Range Experimental and Kinetic Modeling Study of Chain Length Impact on n-Alkanes Autoxidation. Energy \& Fuels 2016, 30, 1294-1303.

(13) Liquid-phase Mechanism Generation For Application To Fuel Oxidation, 2016.

(14) Mielczarek, D. C.; Matrat, M.; Amara, A. B.; Bouyou, Y.; Wund, P.; Starck, L. Toward the Accurate Prediction of Liquid Phase Oxidation of Aromatics: A Detailed Kinetic Mechanism for Toluene Autoxidation. Energy Fuels 2017, 31, 12893-12913.

(15) Câmara, L. D. T.; Monteiro, R. S.; Constantino, A. M.; Aranda, D. A. G.; Afonso, J. C. Oxidative Cracking of Linear Hydrocarbons at Low Temperatures. Chemical Engineering Communications 2010, 198, 416-424.

(16) Camacho Rubio, F.; Diaz-Rodriguez, F.; FernandezGonzalez, J. Oxidacion de n-parafinas in fase liquida.

Anales de Quimica 1980, 76, 375.

(17) Skolniak, M.; Bukrejewski, P.; Frydrych, J. Analysis of Changes in the Properties of Selected Chemical Compounds and Motor Fuels Taking Place During Oxidation Processes. Intech 2015, DOI: $10.5772 / 59805$.

(18) Jensen, R. K.; Korcek, S.; Mahoney, L. R.; Zinbo, M. Liquid-phase autoxidation of organic compounds at elevated temperatures. 1 . The stirred flow reactor technique and analysis of primary products from n-hexadecane autoxidation at 120-18o. degree. C. Journal of the American Chemical Society 1979, 101, 7574-7584.

(19) van Sickle, D. E.; Mill, T.; Mayo, F. R.; Richardson, H.; Gould, C. W. Intramolecular propagation in the oxida- tion of n-alkanes. Autoxidation of n-pentane and n-octane. The Journal of Organic Chemistry 1973, 38, 44354440.

(20) van Sickle, D. E. Oxidation of 2,4,6-trimethylheptane. The Journal of Organic Chemistry 1972, 37, 755-760.

(21) Winkler, D. E.; Hearne, G. W. Liquid phase oxidation of isobutane. Industrial \& Engineering Chemistry 1961, 53, 655-658.

(22) Ben Amara, A.; Kaoubi, S.; Starck, L. Toward an optimal formulation of alternative jet fuels: Enhanced oxidation and thermal stability by the addition of cyclic molecules. Fuel 2016, 173, 98-105.

(23) Saldana, D. A.; Starck, L.; Mougin, P.; Rousseau, B.; Creton, B. Prediction of Flash Points for Fuel Mixtures Using Machine Learning and a Novel Equation. Energy Fuels 2013, 27, 3811-3820.

(24) Saldana, D. A.; Starck, L.; Mougin, P.; Rousseau, B.; Ferrando, N.; Creton, B. Prediction of Density and Viscosity of Biofuel Compounds Using Machine Learning Methods. Energy Fuels 2012, 26, 2416-2426.

(25) Saldana, D. A.; Starck, L.; Mougin, P.; Rousseau, B.; Pidol, L.; Jeuland, N.; Creton, B. Flash Point and Cetane Number Predictions for Fuel Compounds Using Quantitative Structure Property Relationship (QSPR) Methods. Energy Fuels 2011, 25, 3900-3908.

(26) Abdul Jameel, A. G.; Naser, N.; Emwas, A.-H.; Dooley, S.; Sarathy, S. M. Predicting Fuel Ignition Quality Using 1 H NMR Spectroscopy and Multiple Linear Regression. Energy Fuels 2016, 30, 9819-9835.

(27) Dahmen, M.; Marquardt, W. A Novel Group Contribution Method for the Prediction of the Derived Cetane Number of Oxygenated Hydrocarbons. Energy Fuels 2015, 29, 5781-5801.

(28) Just, G.; Pritzkow, W.; Rudolf, M.; Tien, T. D.; Voerckel, V. Estimation of relative Autoxidation Rates of Normal Paraffins, secondary alcohols, and ketones by competitive reactions. J. Prakt. Chem. 1986, 328, 469-474. (29) Stark, M. S.; Wilkinson, J. J.; Smith, J. R. L.; Alfadhl, A.; Pochopien, B. A. Autoxidation of Branched Alkanes in the Liquid Phase. Ind. Eng. Chem. Res. 2011, 50, 817-823.

(30) Sicard, M.; Boulicault, J.; Coulon, K.; Thomasset, C.; Ancelle, J.; Raepsaet, B.; Ser, F. Oxidation stability of jet fuel model molecules evaluated by rapid small scale oxidation tests. In The 13th International Conference on Stability, Handling and Use of Liquid Fuels 2013 IASH 2013, 2013.

(31) Bacha, K.; Ben-Amara, A.; Vannier, A.; Alves-Fortunato, M.; Nardin, M. Oxidation Stability of Diesel/Biodiesel Fuels Measured by a PetroOxy Device and Characterization of Oxidation Products. Energy \& Fuels 2015, 29, 4345-4355.

(32) Bacha, K.; Ben Amara, A.; Alves Fortunato, M.; Wund, P.; Veyrat, B.; Hayrault, P.; Vannier, A.; Nardin, 
M.; Starck, L. Original Experimental Approach for Assessing Transport Fuel Stability. Journal of visualized experiments : JoVE 2016, DOI: 10.3791/54361.

(33) ASTM. ASTM D7545 - og Standard Test Method for Oxidation Stability of Middle Distillate Fuels-Rapid Small Scale Oxidation Test (RSSOT).

(34) European Standards. EN PREN 16o91-2010 Liquid petroleum products. Middle distillates and fatty acid methyl ester fame fuels and blends. Determination of oxidation stability by rapid small scale oxidation method, 2010. (35) Chatelain, K. Oxidation stability of fuels in liquid phase. Ph.D., 2016.

(36) Green, W. H.; Allen, J. W.; Buesser, B. A.; Ashcraft, R. W.; Beran, G. J.; Class, C. A.; Gao, C.; Goldsmith, C. F.; Harper, M. R.; Jalan, A., et al. RMG - Reaction Mechanism Generator, 2013.

(37) Jalan, A.; Ashcraft, R. W.; West, R. H.; Green, W. H. Predicting solvation energies for kinetic modeling. Annual Reports Section" C"(Physical Chemistry) 2010, 106, 211-258. (38) Jalan, A.; West, R. H.; Green, W. H. An Extensible Framework for Capturing Solvent Effects in Computer Generated Kinetic Models. J. Phys. Chem. B 2013, 117, 2955-2970.

(39) Abraham, M. H. Solvent Effects on Transition States and Reaction Rates. Progress in Physical Organic Chemistry; John Wiley \& Sons, Inc, 2007; pp 1-87.

(40) Mintz, C.; Gibbs, J.; Acree, W. E.; Abraham, M. H. Enthalpy of solvation correlations for organic solutes and gases dissolved in acetonitrile and acetone. Thermochimica Acta 2009, 484, 65-69.

(41) Linstrom, P. J.; W.G. Mallard, E.; Standards, N. I. o.; Technology. NIST Chemistry WebBook. NIST Standard Reference Database Number 69, National Institute of Standards and Technology 2001.

(42) Rowley, J. R.; Wilding, W. V.; Oscarson, J. L.; Yang, Y.; Giles, N. F. Design Institute for Physical Properties Data. (DIPPR-AIChE) 2011.

(43) Boss, B. D.; Hazlett, R. N. Oxidation of hydrocarbons in the liquid phase: n-dodecane in a borosilicate glass chamber at 20oC. Canadian Journal of Chemistry 1969, 47, 4175-4182.

(44) Cullis, C. F.; Hirschler, M. M.; Rogers, R. The oxidation of decane in the liquid and gaseous phases. Proceedings of the Royal Society of London. A. Mathematical and Physical Sciences 1981, 375, 543-563.

(45) Syroezhko, A. M.; Potekhin, V. M.; Proskuryakov, V. A. Composition of the products of the liquid phase oxidation of n-decane. Zhurnal Prikladnoi Khimii 1970, 43, 17911798.

(46) Garcia-Ochoa, F.; Romero, A.; Querol, J. Modeling of the thermal n-octane oxidation in the liquid phase. Industrial \& engineering chemistry research 1989, 28, 43-48.

(47) Liu, L.; Guo, Q.-X. Isokinetic Relationship, Isoequilibrium Relationship, and Enthalpy-Entropy Compensation. Chem. Rev. 2oo1, 101, 673-696.

(48) J. H. B. Chenier; S. B. Tong; J. A. Howard. Absolute rate constants for hydrocarbon autoxidation. 25. Rate constants for hydrogen atom abstraction from alkanes by the tert-butylperoxy radical.

(49) Carstensen, H.-H.; Dean, A. M. Rate constants for the abstraction reactions $\mathrm{RO}_{2}+\mathrm{C}_{2} \mathrm{H} 6 ; \mathrm{R}=\mathrm{H}, \mathrm{CH}_{3}$, and $\mathrm{C}_{2} \mathrm{H}_{5}$. Proceedings of the Combustion Institute 2005, 30, 995-1003.

(50) Wang, Z.; Popolan-Vaida, D. M.; Chen, B.; Moshammer, K.; Mohamed, S. Y.; Wang, H.; Sioud, S.; Raji, M. A.; Kohse-Höinghaus, K.; Hansen, N. et al. Unraveling the structure and chemical mechanisms of highly oxygenated intermediates in oxidation of organic compounds. Proceedings of the National Academy of Sciences of the United States of America 2017, 114, 13102-13107.

(51) Snelgrove, D. W.; Lusztyk, J.; Banks, J. T.; Mulder, P.; Ingold, K. U. Kinetic Solvent Effects on Hydrogen-Atom Abstractions: Reliable, Quantitative Predictions via a Single Empirical Equation 1. J. Am. Chem. Soc. 2oo1, 123, 469477.

(52) Nicolle, A.; Cagnina, S.; Bruin, T. de. First-principle based modeling of urea decomposition kinetics in aqueous solutions. Chemical Physics Letters 2016, 664, 149-153. 